\title{
Toxocara infection: seroprevalence and associated risk factors among primary school children in central China
}

\author{
Shuai Wang ${ }^{1, a}$, Haoran $\mathrm{Li}^{1, \mathrm{a}}$, Zhijun Yao ${ }^{1, \mathrm{a}}$, Pengju $\mathrm{Li}^{1}$, Dong Wang ${ }^{1}$, Haizhu Zhang ${ }^{1}$, Qing Xie ${ }^{1}$, Zhenchao Zhang ${ }^{1, *}$, \\ and Xiangrui $\mathrm{Li}^{1,2, *}$ \\ ${ }^{1}$ Xinxiang Key Laboratory of Pathogenic Biology, School of Basic Medical Sciences, Xinxiang Medical University, Xinxiang, 453003 \\ Henan, PR China \\ ${ }^{2}$ MOE Joint International Research Laboratory of Animal Health and Food Safety, College of Veterinary Medicine, Nanjing Agricultural \\ University, Nanjing, 210095 Jiangsu, PR China
}

Received 22 March 2020, Accepted 21 April 2020, Published online 5 May 2020

\begin{abstract}
Toxocariasis is a zoonotic disease that poses a threat to public health worldwide. In the present study, we investigated the seroprevalence of Toxocara infection among primary school children in Henan province, central China, which was previously unknown. Sera from 2451 primary school children were collected from September 2015 to October 2018, and evaluated for anti-Toxocara antibodies by enzyme-linked immunosorbent assay (ELISA). The overall seroprevalence of Toxocara infection was 5.14\% (126/2451). The main risk factors related to Toxocara infection identified in this study were the age of children, residence area of children, contact with cats or dogs, and exposure to soil. Hand washing before eating was considered to be a protective factor. These findings demonstrate that Toxocara infection is relatively common among primary school children in Henan province.
\end{abstract}

Key words: Toxocara, Primary school children, Seroprevalence, Risk factors, Central China.

Résumé - Infection à Toxocara : séroprévalence et facteurs de risque associés chez les enfants des écoles primaires du centre de la Chine. La toxocarose est une zoonose qui représente une menace pour la santé publique dans le monde. Dans la présente étude, nous avons étudié la séroprévalence de l'infection à Toxocara chez les enfants des écoles primaires de la province du Henan, en Chine centrale, qui était auparavant inconnue. Des sérums de 2451 enfants du primaire ont été collectés de septembre 2015 à octobre 2018 et évalués pour les anticorps anti-Toxocara par dosage immuno-enzymatique (ELISA). La séroprévalence globale de l'infection à Toxocara était de 5,14\% (126/2451). Les principaux facteurs de risque liés à l'infection à Toxocara identifiés dans cette étude étaient l'âge des enfants, la zone de résidence des enfants, le contact avec des chats ou des chiens et l'exposition au sol. Le lavage des mains avant de manger a été considéré comme un facteur de protection. Ces résultats démontrent que l'infection à Toxocara est relativement courante chez les enfants des écoles primaires de la province du Henan.

\section{Introduction}

Toxocariasis is a worldwide zoonotic infection caused by the ascarid larvae of the Toxocara genus, including Toxocara canis (T. canis) and Toxocara cati (T. cati). Toxocara canis acts as the most frequent cause of toxocariasis, whereas $T$. cati is less common [16]. Their definitive hosts are domestic dogs and cats, respectively. Humans are accidental hosts who become infected by ingesting infective eggs or undercooked meat/viscera of infected paratenic hosts. After ingestion, the eggs hatch and larvae migrate through the intestine and can be carried to multiple organs (heart, liver, lungs, muscle, brain, and eyes) via the bloodstream, causing local reactions and mechanical damage that causes clinical toxocariasis [28]. Infection in humans leads to various disorders accompanied by relevant manifestations. There are four commonly described disorders: convert toxocariasis (CT), neurotoxocariasis (NT) (e.g., eosinophilic meningoencephalitis), ocular larva migrans (OLM), and visceral larva migrans (VLM) [21, 28].

Children usually become infected by accidentally ingesting embryonated eggs of $T$. canis or $T$. cati from the contaminated environment (e.g., soil and water) [24, 27] and dirty hands or, occasionally, by eating invertebrates, such as earthworms [4]. Consumption of undercooked meat from paratenic hosts

*Corresponding authors: zhangzhenchao525@163.com, lixiangrui@njau. edu.cn

${ }^{\text {a }}$ Authors who contributed equally to this paper.

This is an Open Access article distributed under the terms of the Creative Commons Attribution License (https://creativecommons.org/licenses/by/4.0), which permits unrestricted use, distribution, and reproduction in any medium, provided the original work is properly cited. 
that contain encapsulated larvae can also result in toxocariasis [14, 34].

In China, $T$. canis and $T$. cati have been widely detected in dogs and cats, respectively $[9,32,36]$. An increasing number of clinical cases of toxocariasis have been reported in children (Table 1; [18, 20, 33, 37-39]). However, little is known about the seroprevalence of Toxocara infection among children in China (Table 2; [5, 6, 19, 20]). Most surveys were published in local journals in Chinese, and are not readily accessible to international readers. Furthermore, reports on Toxocara seroprevalence among students in primary school in Henan province, central China were still lacking. Consequently, the aim of the current study was to investigate Toxocara seroprevalence and relevant risk factors among students in primary school in Henan province.

\section{Materials and methods}

\section{Ethics statements}

In the current study, all protocols were reviewed and approved by the Ethics Committee of Xinxiang Medical University (Ref. no. 2015018).

\section{Study site and sample collection}

Blood samples were collected from 2451 primary school children in four cities of Henan province, as previously described [31]. The same sera were used in both studies.

\section{Antibodies to Toxocara}

A commercial Toxocara IgG ELISA kit (Diagnostic Automation Inc., Woodland Hills, CA, USA) was used to detect anti-Toxocara IgG antibodies. Both negative and positive controls were provided in the kit and used in each test. Samples were considered positive on the basis of absorption that was no less than 0.3 OD units. Samples with inconclusive results were tested again. All the operations were performed according to the manufacturer's instructions $[5,35]$. The sensitivity and specificity of the ELISA were $87.5 \%$ and $93.3 \%$, respectively.

\section{Statistical analysis}

Statistical analysis was performed using SPSS 20 software for Windows (SPSS Inc., Chicago, IL, USA). Statistical analyses of Toxocara prevalence in different variables were performed using a $\chi^{2}$-test. A $p$-value of less than 0.05 was deemed statistically significant.

\section{Results}

As shown in Table 3, the overall seroprevalence of Toxocara infection among primary school children in Henan province was $5.14 \%$. Toxocara seroprevalence among the children living in Xinxiang, Zhengzhou, Zhumadian and Nanyang were $3.08 \%, 5.90 \%, 4.52 \%$, and $7.08 \%$, respectively.
Table 1. Reported clinical cases of toxocariasis in children in the People's Republic of China.

\begin{tabular}{lccc}
\hline Provinces/cities & Year & No. of cases & Reference \\
\hline Chengdu, Sichuan & 1996 & 3 & Yang et al. [33] \\
Chengdu, Sichuan & 1999 & 63 & Luo et al. [20] \\
Changsha & 2008 & 1 & Lei et al. [18] \\
Shanghai & $2007-2009$ & 12 & Zhou et al. [38] \\
Shanghai & $2009-2011$ & 28 & Zhou et al. [39] \\
Jiangsu & 2012 & 1 & Zhang et al. [37] \\
\hline
\end{tabular}

The prevalence of Toxocara antibodies varied significantly with the place of residence $(p=0.014)$.

There was no significant difference in the seroprevalence of Toxocara between boys and girls $(5.28 \%$ vs. $4.99 \%$, $\chi^{2}=0.101, p=0.751$ ) (Table 3). The overall Toxocara seroprevalence increased with increasing age (Table 3$)$. In comparison to groups of 6-7 year-olds (3.54\%), and 8-9 year-olds (5.23\%), the Toxocara seroprevalence amongst 10-11 year-olds was highest $(6.60 \%)$.

The seroprevalence of Toxocara infection in children living in rural areas was significantly higher than those living in urban areas $\left(\chi^{2}=4.799, p=0.028\right)$, and the rate was significantly higher in children in contact with cats $\left(\chi^{2}=4.328\right.$, $p=0.037)$ and $\operatorname{dogs}\left(\chi^{2}=10.051, p=0.002\right)$. Moreover, the probability of infection with Toxocara was significantly increased in children in contact with soil compared to those with no contact $\left(5.69 \%\right.$ vs. $\left.3.64 \%, \chi^{2}=4.153, p=0.042\right)$. Children with the behavior of washing hands before eating exhibited lower seropositive rates for Toxocara than those without $\left(4.26 \%\right.$ vs. $\left.7.02 \%, \chi^{2}=8.306, p=0.004\right)$.

\section{Discussion}

The overall seroprevalence for Toxocara infection was $5.14 \%$ in primary school children in Henan province. The seroprevalence obtained in this study was lower than that of other provinces in China such as Sichuan $(10.96 \%$ and $11.49 \%)[19,20]$, and Shandong and Jilin provinces (19.27\%) [6]. Compared to other countries and regions, the total Toxocara seropositive rate in Henan province was also lower than $86.1 \%$ reported in children aged 7-17 years from Makoko, an urban slum community in Nigeria [12], $86.75 \%$ among students in primary schools from the capital area of the Republic of the Marshall Islands [10], $12.02 \%$ in the Amecameca and Chalco regions of México [7], 29.0\% in Aragua state, Venezuela [22], and $10.0 \%$ in Serbia [11]. However, the seropositive rate was higher than that observed in Iran $(1.39-3.8 \%)$ [13, 15, 16]. Several factors such as age of children, sample sizes, the specificity and sensitivity of the detection methods used, various climatic and geographical conditions, hygiene habits, and lifestyle of the population assessed could have contributed to the differences observed in seroprevalence rates.

The present study showed that geographical origin is a risk factor. The differences in seropositive rates among the different regions of Henan may be attributed to local food habits, climate condition, densities of population, and the number of stray dogs and cats. In this study, the seroprevalence value 
Table 2. Seroprevalence of Toxocara infection in children in the People's Republic of China.

\begin{tabular}{|c|c|c|c|c|c|c|}
\hline Provinces/cities & Year of sampling & No. of tested & No. of positive & Prevalence $(\%)$ & Method & Reference \\
\hline Sichuan & 1993 & 657 & 72 & 10.96 & ELISA $^{\mathrm{a}}$ & Luo et al. [19] \\
\hline Chengdu, Sichuan & 1999 & 557 & 64 & 11.49 & ELISA & Luo et al. [20] \\
\hline Weihai and Qingdao, Shandong & $2011-2013$ & 133 & 20 & 15.04 & ELISA & Cong et al. [5] \\
\hline Shandong and Jilin & 2013-2014 & 1458 & 281 & 19.27 & ELISA & Cong et al. [6] \\
\hline
\end{tabular}

${ }^{a}$ ELISA: enzyme-linked immunosorbent assay.

Table 3. Seroprevalence of Toxocara infection in primary school children in Henan province, central China.

\begin{tabular}{|c|c|c|c|c|c|c|}
\hline Variable & No. of tested & No. of positive & Prevalence $(\%)$ & $95 \% \mathrm{CI}$ & $\chi^{2}$ & $p$-value \\
\hline \multicolumn{7}{|l|}{ Region } \\
\hline Xinxiang & 585 & 18 & 3.08 & $1.68-4.48$ & \multirow[t]{4}{*}{10.637} & \multirow[t]{4}{*}{0.014} \\
\hline Zhengzhou & 696 & 41 & 5.90 & $4.14-7.64$ & & \\
\hline Zhumadian & 619 & 28 & 4.52 & $2.89-6.16$ & & \\
\hline Nanyang & 551 & 39 & 7.08 & $4.94-9.22$ & & \\
\hline \multicolumn{7}{|l|}{ Sex } \\
\hline Male & 1289 & 68 & 5.28 & $4.06-6.50$ & \multirow[t]{2}{*}{0.101} & \multirow[t]{2}{*}{0.751} \\
\hline Female & 1162 & 58 & 4.99 & $3.74-6.24$ & & \\
\hline \multicolumn{7}{|l|}{ Age (years) } \\
\hline $6-7$ & 819 & 29 & 3.54 & $2.28-4.81$ & \multirow[t]{3}{*}{8.033} & \multirow[t]{3}{*}{0.018} \\
\hline $8-9$ & 784 & 41 & 5.23 & $3.67-6.79$ & & \\
\hline $10-11$ & 848 & 56 & 6.60 & $4.93-8.28$ & & \\
\hline \multicolumn{7}{|l|}{ Residence area } \\
\hline Urban & 1127 & 46 & 4.08 & $2.93-5.24$ & \multirow[t]{2}{*}{4.799} & \multirow[t]{2}{*}{0.028} \\
\hline Rural & 1324 & 80 & 6.04 & $4.76-7.33$ & & \\
\hline \multicolumn{7}{|c|}{ Contact with cats } \\
\hline No & 1462 & 64 & 4.38 & $3.33-5.43$ & \multirow[t]{2}{*}{4.328} & \multirow[t]{2}{*}{0.037} \\
\hline Yes & 989 & 62 & 6.27 & $4.76-7.78$ & & \\
\hline \multicolumn{7}{|c|}{ Contact with dogs } \\
\hline No & 1328 & 51 & 3.84 & $2.81-4.87$ & \multirow[t]{2}{*}{10.051} & \multirow[t]{2}{*}{0.002} \\
\hline Yes & 1123 & 75 & 6.68 & $5.22-8.14$ & & \\
\hline \multicolumn{7}{|c|}{ Exposure to soil } \\
\hline No & 659 & 24 & 3.64 & $2.21-5.07$ & \multirow[t]{2}{*}{4.153} & \multirow[t]{2}{*}{0.042} \\
\hline Yes & 1792 & 102 & 5.69 & $4.62-6.76$ & & \\
\hline \multicolumn{7}{|c|}{ Hand washing before eating } \\
\hline No & 784 & 55 & 7.02 & $5.23-8.80$ & \multirow[t]{3}{*}{8.306} & \multirow[t]{3}{*}{0.004} \\
\hline Yes & 1667 & 71 & 4.26 & $3.29-5.23$ & & \\
\hline Total & 2451 & 126 & 5.14 & $4.27-6.02$ & & \\
\hline
\end{tabular}

for boys was nearly equal to that of girls, indicating that the exposure levels of both sexes were very similar, and thus male or female sex was not a critical risk factor associated with Toxocara infection. This finding was consistent with other similar reports $[7,13]$.

It has been found in numerous studies that Toxocara seroprevalence is positively correlated with the age of children $[12,30]$. In the current study, similarly, Toxocara seroprevalence also exhibited a positive correlation with the age of children, with a progressive and significant pattern. It has been hypothesized that this phenomenon results from increasing years of exposure as the child grows, and a generally highly contaminated environment.

The present study found that children with a history of contact with dogs or cats showed a higher tendency to acquire Toxocara infection than those who do not. A number of studies showed the presence of embryonated $T$. canis and $T$. cati eggs on the hair of dogs and cats, respectively, indicating that direct contact with dogs or cats may be a potential route of infection $[1,8,23]$. If children touch dogs and cats frequently, the possibility of accidentally ingesting embryonated $T$. canis or $T$. cati eggs from the hair increases, which results in a higher risk of infection. The seropositive rate of Toxocara in children living in rural areas was significantly higher than that in urban areas, which was consistent with other reports $[16,29]$. The explanation for this observation is that the higher number of stray and domesticated dogs and cats in rural areas may have increased the degree of environmental contamination with Toxocara eggs. Poor hygiene habits in rural areas can also lead to a higher incidence of toxocariasis.

Soil contamination with Toxocara eggs is considered to be the main source of human infections [2, 25, 26]. The present study also revealed that exposure to soil was related to Toxocara infection in primary school children, indicating that soil contamination by dog and cat feces is widespread in these areas. In the future, more research is needed to evaluate the 
prevalence of Toxocara eggs in the soil of local parks and primary schools.

Additionally, hand washing before eating has been verified as a protective factor related to Toxocara seroprevalence in this study. This finding is in line with other similar surveys [3, 17].

\section{Conclusion}

In conclusion, the present study revealed for the first time that Toxocara infection in primary school children is relatively common in Henan province, China. Prevention approaches including cleaning hands after contact with soil, cats or dogs and before eating, reducing soil contamination by dog or cat feces in public areas, and treating dogs and cats with anthelmintics to reduce Toxocara burdens, can be beneficial to minimize exposure to Toxocara spp.

\section{Conflict of interest statement}

We declare that we have no conflict of interest.

Acknowledgements. The current work received support from the National Natural Science Foundation of China (No. 81702025), the Science and Technology Planning Project of Henan Province (Nos. 182102310220 and 182102310431) and the Doctoral Scientific Research Activation Foundation of Xinxiang Medical University (Nos. XYBSKYZZ201504 and XYBSKYZZ201631).

\section{References}

1. Bakhshani A, Maleki M, Haghparast A, Parande Shirvan S, Borji H. 2019. A survey on Toxocara cati eggs on the hair of stray cats: a potential risk factor for human toxocariasis in Northeastern Iran. Comparative Immunology, Microbiology and Infectious Diseases, 64, 10-13.

2. Berenji F, Movahedi Rudy AG, Fata A, Tavassoli M, Mousavi Bazaz M, Salehi Sangani G. 2015. Soil contamination with Toxocara spp. Eggs in public parks of Mashhad and Khaf, North East of Iran. Iranian Journal of Parasitology, 10(2), 286-289.

3. Cassenote AJ, Lima AR, Pinto Neto JM, Rubinsky-Elefant G. 2014. Seroprevalence and modifiable risk factors for Toxocara spp. in Brazilian schoolchildren. PLoS Neglected Tropical Diseases, 8(5), e2830.

4. Cianferoni A, Schneider L, Schantz PM, Brown D, Fox LM. 2006. Visceral larva migrans associated with earthworm ingestion: clinical evolution in an adolescent patient. Pediatrics, 117(2), e336-e339.

5. Cong W, Zhang XX, Zhou N, Yu CZ, Chen J, Wang XY, Li B, Qian AD, Zhu XQ. 2014. Toxocara seroprevalence among clinically healthy individuals, pregnant women and psychiatric patients and associated risk factors in Shandong province, Eastern China. PLoS Neglected Tropical Diseases, 8(8), e3082.

6. Cong W, Meng QF, You HL, Zhou N, Dong XY, Dong W, Wang XY, Qian AD, Zhu XQ. 2015. Seroprevalence and risk factors of Toxocara infection among children in Shandong and Jilin provinces, China. Acta Tropica, 152, 215-219.

7. Cortes NN, Nunez CR, Guiliana BG, Garcia PA, Cardenas RH. 2015. Presence of anti-Toxocara canis antibodies and risk factors in children from the Amecameca and Chalco regions of Mexico. BMC Pediatrics, 15, 65.
8. El-Tras WF, Holt HR, Tayel AA. 2011. Risk of Toxocara canis eggs in stray and domestic dog hair in Egypt. Veterinary Parasitology, 178(3-4), 319-323.

9. Fang F, Li J, Huang T, Guillot J, Huang W. 2015. Zoonotic helminths parasites in the digestive tract of feral dogs and cats in Guangxi, China. BMC Veterinary Research, 11, 211.

10. Fu CJ, Chuang TW, Lin HS, Wu CH, Liu YC, Langinlur MK, Lu MY, Hsiao WW, Fan CK. 2014. Seroepidemiology of Toxocara canis infection among primary schoolchildren in the capital area of the Republic of the Marshall Islands. BMC Infectious Diseases, 14, 261.

11. Gabrielli S, Tasic-Otasevic S, Ignjatovic A, Fraulo M, TrenkicBozinovic M, Momcilovic S, Cancrini G. 2017. Seroprevalence and risk factors for Toxocara canis Infection in Serbia during 2015. Foodborne Pathogens and Disease, 14(1), 43-49.

12. Gyang PV, Akinwale OP, Lee YL, Chuang TW, Orok AB, Ajibaye O, Liao CW, Chen PC, Chou CM, Huang YC, Barghouth U, Fan CK. 2015. Seroprevalence, disease awareness, and risk factors for Toxocara canis infection among primary schoolchildren in Makoko, an urban slum community in Nigeria. Acta Tropica, 146, 135-140.

13. Hosseini-Safa A, Mousavi SM, Bahadoran Bagh Badorani M, Ghatreh Samani M, Mostafaei S, Yousofi Darani H. 2015. Seroepidemiology of toxocariasis in children (5-15 yr old) referred to the pediatric clinic of Imam Hossein Hospital, Isfahan, Iran. Iranian Journal of Parasitology, 10(4), 632-637.

14. Karaca I, Mentes J, Nalcaci S. 2018. Toxocara neuroretinitis associated with raw meat consumption. Turkish Journal of Ophthalmology, 48(5), 258-261.

15. Khoshsima Shahraki M, Dabirzadeh M, Afshari M, Maroufi Y. 2017. Epidemiological study of Toxocara canis in children under 14-years-old and dogs in Zabol and Chabahar districts, Southeast of Iran. Iranian Journal of Parasitology, 12(1), 101-107.

16. Khoshsima-Shahraki M, Dabirzadeh M, Azizi H, Khedri J, Djahed B, Neshat AA. 2019. Seroepidemiology of Toxocara canis in children under 14 years referring to laboratories of Sistan and Baluchestan province in Southeast of Iran. Iranian Journal of Parasitology, 14(1), 89-94.

17. Kyei G, Ayi I, Boampong JN, Turkson PK. 2015. Seroepidemiology of Toxocara canis infection in children attending four selected health facilities in the central region of Ghana. Ghana Medical Journal, 49(2), 77-83.

18. Lei SB, Guo XJ, Tang LS, Li Y. 2008. A case of ocular toxocariasis. Chinese Journal of Ocular Fundus Diseases, 24(4), 299-300. (in Chinese).

19. Luo CH, Yang CL, Mao M, Li Q, Luo ZJ, Chen SW. 1993. Prevalence of Toxocara canis infection in children aged 0 to 2 years old in rural areas of Sichuan, China. Chinese Journal of Pediatrics, 31(05), 279-281. (in Chinese).

20. Luo ZJ, Wang GX, Yang CI, Luo CH, Cheng SW, Liao L. 1999. Detection of circulating antigens and antibodies in Toxocara canis infection among children in Chengdu, China. Journal of Parasitology, 85(2), 252-256.

21. Ma G, Holland CV, Wang T, Hofmann A, Fan CK, Maizels RM, Hotez PJ, Gasser RB. 2018. Human toxocariasis. Lancet Infectious Diseases, 18(1), e14-e24.

22. Martinez M, Garcia H, Figuera L, Gonzalez V, Lamas F, Lopez K, Mijares V, Corrales Y, Lares M, Ferrer E. 2015. Seroprevalence and risk factors of toxocariasis in preschool children in Aragua state, Venezuela. Transactions of the Royal Society of Tropical Medicine and Hygiene, 109(9), 579-588.

23. Merigueti Y, Santarem VA, Ramires LM, da Silveira Batista A, da Costa Beserra LV, Nuci AL, de Paula Esposte TM. 2017. Protective and risk factors associated with the presence of Toxocara spp. eggs in dog hair. Veterinary Parasitology, 244, 39-43. 
24. Mizgajska-Wiktor H, Jarosz W, Fogt-Wyrwas R, Drzewiecka A. 2017. Distribution and dynamics of soil contamination with Toxocara canis and Toxocara cati eggs in Poland and prevention measures proposed after 20 years of study. Veterinary Parasitology, 234, 1-9.

25. Otero D, Alho AM, Nijsse R, Roelfsema J, Overgaauw P, Madeira de Carvalho L. 2018. Environmental contamination with Toxocara spp. eggs in public parks and playground sandpits of Greater Lisbon, Portugal. Journal of Infection and Public Health, 11(1), 94-98.

26. Papavasilopoulos V, Pitiriga V, Birbas K, Elefsiniotis J, Bonatsos G, Tsakris A. 2018. Soil contamination by Toxocara canis and human seroprevalence in the Attica region, Greece. Germs, 8(3), 155-161.

27. Pezeshki A, Haniloo A, Alejafar A, Mohammadi-Ghalehbin B. 2017. Detection of Toxocara spp. eggs in the soil of public places in and around of Ardabil city, Northwestern Iran. Iranian Journal of Parasitology, 12(1), 136-142.

28. Rostami A, Ma G, Wang T, Koehler AV, Hofmann A, Chang BCH, Macpherson CN, Gasser RB. 2019. Human toxocariasis a look at a neglected disease through an epidemiological "prism". Infection, Genetics and Evolution, 74, 104002.

29. Shokouhi S, Abdi J. 2018. Seroprevalence of Toxocara in children from urban and rural areas of Ilam province, West Iran. Osong Public Health and Research Perspectives, 9(3), 101-104.

30. Sowemimo OA, Lee YL, Asaolu SO, Chuang TW, Akinwale OP, Badejoko BO, Gyang VP, Nwafor T, Henry E, Fan CK. 2017. Seroepidemiological study and associated risk factors of Toxocara canis infection among preschool children in Osun State, Nigeria. Acta Tropica, 173, 85-89.

31. Wang S, Yao Z, Li H, Li P, Wang D, Zhang H, Xie Q, Zhang Z, Li X. 2020. Seroprevalence and risk factors of Toxoplasma gondii infection in primary school children in Henan province, central China. Parasite, 27, 23.

32. Yang Y, Liang H. 2015. Prevalence and risk factors of intestinal parasites in cats from China. BioMed Research International, 2015, 967238

33. Yang C, Luo C, Jia C, Luo Z, Chen S, Wang G. 1996. Three cases of asthmatic bronchitis caused by Toxocara infection. Journal of Applied Clinical Pediatrics, 11(1), 54-55. (in Chinese).

34. Yang HK, Woo SJ, Hwang JM. 2014. Toxocara optic neuropathy after ingestion of raw meat products. Optometry and Vision Science, 91(11), e267-e273.

35. Yang GL, Zhang XX, Shi CW, Yang WT, Jiang YL, Wei ZT, Wang CF, Zhao Q. 2016. Seroprevalence and associated risk factors of Toxocara infection in Korean, Manchu, Mongol, and Han ethnic groups in northern China. Epidemiology and Infection, 144(14), 3101-3107.

36. Yu Z, Ruan Y, Zhou M, Chen S, Zhang Y, Wang L, Zhu G, Yu Y. 2018. Prevalence of intestinal parasites in companion dogs with diarrhea in Beijing, China, and genetic characteristics of Giardia and Cryptosporidium species. Parasitology Research, 117(1), 35-43.

37. Zhang HF, Hua HY, Wang W. 2015. Pediatric ocular toxocariasis in Jiangsu province, Eastern China. Southeast Asian Journal of Tropical Medicine and Public Health, 46(1), 8-14.

38. Zhou M, Chang Q, Xu GZ, Chen RJ, Bi YW, Jiang R. 2010. Application of intraocular fluid examination in the diagnosis of pediatric uveitis. Chinese Journal of Ophthalmology and Otorhinolaryngology, 10(3), 160-162. (in Chinese).

39. Zhou M, Chang Q, Gonzales JA, Chen Q, Zhang Y, Huang X, Xu G, Wang W, Jiang R. 2012. Clinical characteristics of ocular toxocariasis in Eastern China. Graefe's Archive for Clinical and Experimental Ophthalmology, 250(9), 1373-1378.

Cite this article as: Wang S, Li H, Yao Z, Li P, Wang D, Zhang H, Xie Q, Zhang Z \& Li X. 2020. Toxocara infection: seroprevalence and associated risk factors among primary school children in central China. Parasite 27, 30.

\section{PARASTE}

An international open-access, peer-reviewed, online journal publishing high quality papers on all aspects of human and animal parasitology

Reviews, articles and short notes may be submitted. Fields include, but are not limited to: general, medical and veterinary parasitology; morphology, including ultrastructure; parasite systematics, including entomology, acarology, helminthology and protistology, and molecular analyses; molecular biology and biochemistry; immunology of parasitic diseases; host-parasite relationships; ecology and life history of parasites; epidemiology; therapeutics; new diagnostic tools.

All papers in Parasite are published in English. Manuscripts should have a broad interest and must not have been published or submitted elsewhere. No limit is imposed on the length of manuscripts.

Parasite (open-access) continues Parasite (print and online editions, 1994-2012) and Annales de Parasitologie Humaine et Comparée (1923-1993) and is the official journal of the Société Française de Parasitologie. 